\title{
Patient-clinician communication about end-of-life care for Dutch and US patients
} with COPD

\author{
D.J.A. Janssen*,\#, , J.R. Curtis ${ }^{+}$, D.H. Au ${ }^{\S, f}$, M.A. Spruit*, L. Downey, \\ J.M.G.A. Schols**, E.F.M. Wouters ${ }^{\star, \# \#}$ and R.A. Engelberg ${ }^{+}$
}

ABSTRACT: Improving patient-clinician communication about end-of-life care is important in order to enhance quality of care for patients with chronic obstructive pulmonary disease (COPD). Our objective was to compare quality of patient-clinician communication about end-of-life care, and endorsement of barriers and facilitators to this communication in the Netherlands and the USA.

The present study was an analysis of survey data from 122 Dutch and 391 US outpatients with COPD. We compared quality of patient-clinician communication about end-of-life care (Quality of Communication questionnaire) and barriers and facilitators to communication about end-of-life care (Barriers and Facilitators Questionnaire) between the Netherlands and the USA, controlling for patients' demographic and illness characteristics.

Although Dutch patients in this study had worse lung function and disease-specific health status than US patients, Dutch patients reported lower quality of communication about end-of-life care (median score 0.0 (interquartile range $0.0-2.0)$ versus $1.4(0.0-3.6)$; adjusted $p<0.005$ ). Clinicians in both countries rarely discussed life-sustaining treatment preferences, prognoses, dying processes or spiritual issues.

Quality of communication about end-of-life care needs to improve in the Netherlands and the USA. Future studies to improve this communication should be designed to take into account international differences and patient-specific barriers and facilitators to communication about end-of-life care.

KEYWORDS: Advance care planning, chronic obstructive pulmonary disease, communication, end-of-life care, palliative care

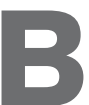
ecause chronic obstructive pulmonary disease (COPD) is a major cause of mortality worldwide [1], the provision of high-quality palliative care to these patients is an important priority. Understanding and improving patient-clinician communication about endof-life care is one way to ensure the delivery of high-quality palliative care [2]. Studies of patientclinician communication about end-of-life care in COPD have been performed primarily in the USA. These studies have identified areas for improvement in communication about end-of-life care as well as barriers and facilitators to communication about end-of-life care in COPD [3, 4].

Important regional differences may exist in patient-clinician communication about end-of-lifecare [3]. Indeed, patient involvement in decisions about life-sustaining treatments differs between North America and Europe [5], and international differences exist in the provision of end-of-life care. For example, a higher proportion of US than European patients die in the intensive care unit (ICU) [6] and participation of palliative care teams in European ICUs remains uncommon, while it occurs more frequently in the USA [7, 8]. Furthermore, Dutch patients with chronic diseases are more informed about treatment options and more involved in treatment decisions than US patients [9]. Lastly, a recent report concerning the quality of death across the world ranked the Netherlands higher than the USA [10]. These studies would suggest that communication about end-of-life care may be better in the Netherlands than in the USA.

Future efforts to improve communication about end-of-life care for patients with COPD may benefit from an understanding of international differences in quality of communication about end-of-life care and the barriers and facilitators to

\section{AFFILIATIONS}

*Program Development Centre, $\mathrm{CIRO}$, Centre of Expertise for Chronic Organ Failure,

"Proteion Thuis, Horn, \#CAPHRI,

**Dept of General Practice, Nursing Home Medicine, Faculty of Health Medicine and Life sciences/CAPHRI, Maastricht University, and \#\#Dept of Respiratory Medicine, Maastricht University Medical Centre+, Maastricht, the Netherlands. +Division of Pulmonary and Critical Care Medicine, Dept of Medicine, Harborview Medical Center, ${ }^{\S}$ Health Services Research and Development, Veterans Affairs Puget Sound Health Care System, and ${ }^{\dagger}$ Dept of Medicine, University of Washington, Seattle, WA, USA.

CORRESPONDENCE

D.J.A. Janssen

Program Development Centre, CIRO+ Centre of Expertise for Chronic Organ Failure

Hornerheide 1

6085 NM Horn

The Netherlands

E-mail: daisyjanssen@proteion.nl

Received:

Oct 082010

Accepted after revision:

Dec 222010

First published online:

Jan 132011 
this communication. Based on the prior research, we hypothesised that Dutch patients with COPD would be more involved in decision-making about their care at the end of life and report higher quality of patient-clinician communication about endof-life care.

We sought to compare the quality of patient-clinician communication about end-of-life care and the endorsement of barriers and facilitators to patient-clinician communication about end-of-life care in patients with COPD in the Netherlands and in the USA.

\section{MATERIALS AND METHODS Study design}

The present study is an analysis of baseline data from three studies: 1) a Dutch longitudinal observational study of selfperceived symptoms and care needs of patients with severe COPD [11, 12]; 2) a randomised controlled trial designed to improve quality of communication for patients with COPD in the USA [13]; and 3) a cross-sectional observational study concerning quality of communication in patients with severe COPD in the USA [3].

\section{Study population}

The study population consisted of 513 outpatients with COPD. Diagnosis of COPD was based on airflow obstruction as defined by the Global Initiative for Chronic Obstructive Lung Disease (GOLD) criteria [14]. The Dutch dataset consisted of 124 outpatients with moderate to very severe COPD [12]. Patients were recruited by their clinical specialist at one university and two general hospitals, and data were collected in 2008 and 2009. The first US dataset consisted of 376 patients with COPD from the Veterans Affairs (VA) Puget Sound Health Care System (Seattle, WA, USA), recruited between 2004 and 2007 [13]. The second US dataset consisted of 115 patients with severe COPD [3]. These patients were identified through ambulatory pulmonary clinics in three hospitals (one university hospital, one university-affiliated hospital and one VA Medical Center) and through an oxygen delivery company between 1999 and 2002 in Seattle. The final sample included 122 Dutch and 391 US patients with COPD who had valid responses for the primary outcome measure (Quality of Communication (QOC) questionnaire) and the covariates included in the regression models at study enrollment $(83.4 \%$ of the original datasets). All procedures were approved by institutional review boards at all institutions (see online supplement).

\section{Outcome measures}

QOC questionnaire

The primary outcome of interest was quality of communication, assessed with the QOC questionnaire [3, 15]. The QOC questionnaire consists of 13 items that form two domains (general communication and communication about end-of-life care). Patients were asked to rate how good their doctor is at each of these items on a scale of $0-10$, with 0 indicating "the very worst" and 10 indicating "the very best." Patients were offered two additional response options: "my doctor did not do this" and "don't know". Domain scores were the average from all endorsed items and were calculated for patients who had at least three valid items for the general communication domain and at least four valid items for the end-of-life communication domain. Scores for both domains range from 0 (worst) to 10 (best). The answer "my doctor did not do this" was replaced by a score of " 0 ", while "don't know" was replaced by the median domain score of the valid items for the individual, as suggested by the QOC questionnaire developers [3, 15].

\section{Life-sustaining treatment preferences}

Patients' preferences in their current health state for cardiopulmonary resuscitation (CPR) and invasive mechanical ventilation (MV) were assessed using two validated questions, previously used in patients with COPD [16]. Response options were "yes", "no", or "don't know" (see online supplement for details). In addition, patients reported whether they had discussed their treatment preferences with their clinician, using a previously developed question [15].

\section{Barriers and Facilitators Questionnaire}

Barriers and facilitators to communication about end-of-life care were assessed using the Barriers and Facilitators Questionnaire (BFQ) [4]. The BFQ consists of 15 barriers and 11 facilitators to communication about end-of-life care. For each barrier and facilitator, the respondent was asked if the item applied to his/her situation and it was scored dichotomously (0 if not applicable and 1 if applicable) [4].

\section{Covariates}

The following patient characteristics were obtained by selfreport: age, sex, marital status, race, education and comorbidities (myocardial infarction, congestive heart failure, stomach ulcer, diabetes, cancer and liver disease). We also collected data on the specialty of the treating clinician. All patients had spirometry performed. Forced expiratory volume in $1 \mathrm{~s}$ (FEV1) was expressed as \% predicted reference values [17]. Patients were asked to rate their health status on a five-point scale (excellent, very good, good, fair and poor) [18]. For assessment of disease-specific health status, participants completed the St George's Respiratory Questionnaire (SGRQ) [19]. The SGRQ provides a total score and three domain scores (symptoms, activities and impact) ranging from 0 (optimal) to 100 (worst) points.

\section{Statistics}

Analyses included descriptive statistics using frequencies for categorical variables, and means and standard deviations or medians and interquartile ranges (IQRs) for continuous variables, depending on the variable distribution. Patient characteristics were compared using unpaired t-tests or Mann-Whitney U-tests (as appropriate) for continuous variables and Chi-squared tests for categorical variables. Our first step was to compare the two US study samples to ensure that they were similar for the primary outcome. QOC end-of-life care domain scores were similar in these two US samples, after adjusting for patient characteristics and clustering for clinician, allowing us to combine them for analyses (see online supplement).

In order to examine the association of country with the quality of patient-clinician communication about end-of-life care, we used linear regression analysis with robust standard errors, adjusting for patient's demographic and clinical characteristics. Since limited data are available on potential predictors of quality of communication about end-of-life care in COPD, 
models were constructed by including variables that were possible confounders, defined as a $\mathrm{p}$-value $\leqslant 0.20$. A priori, sex was included as a covariate because it was unequally represented in our comparison samples. The variables entered in the final regression models were age, sex, race (Caucasian and non-Caucasian), marital status (living alone or living with a partner), FEV1, SGRQ total score, and medical history of myocardial infarction, congestive heart failure or diabetes. There were several covariates that did not confound the relationship between country and communication scores $(\mathrm{p}>0.20)$ and were not included in the final model, including educational level (less than high school, or high school or more), speciality of the treating clinician (chest clinician or primary care clinician/geriatrician) and other comorbidities. Since clinicians could have referred more than one patient, this analysis was clustered by clinician.

We also compared individual QOC item scores between Dutch and US patients using the same analytic approach: linear regression analysis with robust standard errors, clustered by clinician and adjusting for the same patient characteristics identified above. Finally, because BFQ items and preferences for life-sustaining treatments were scored dichotomously, we modelled logistic regression analyses, controlling for the same patient characteristics identified for the primary QOC questionnaire analyses and clustered by clinician. SPSS 17.0 (IBM, Somers, NY, USA) was used to develop descriptive statistics; STATA 11.1 (StataCorp, College Station, TX, USA) was used for the regression analyses. A two-sided level of significance was set at $\mathrm{p} \leqslant 0.05$ [20].

\section{RESULTS}

\section{Patient characteristics}

The current study includes 122 Dutch and 391 US patients with COPD. The majority of the patients had severe to very severe COPD (GOLD stage III or IV). Dutch patients had lower FEV1 and worse disease-specific health status. All Dutch patients were Caucasian. Most US patients were male and a lower proportion of US patients were married or living with a partner. All patients in the Dutch sample rated care and communication from a chest clinician, as compared with $44 \%$ of the US patients; the rest of the US patients rated care and communication from geriatricians or primary care clinicians. Finally, a higher proportion of patients from the US sample reported myocardial infarction or liver disease (table 1).

\section{Communication about end-of-life care}

General communication domain scores were rated high, while communication about end-of-life care domain scores were rated low (fig. 1). Dutch patients reported statistically significantly lower QOC general and end-of-life care domain scores than US patients. After controlling for country, three other patient characteristics were also statistically significant predictors for higher QOC end-of-life care scores: 1) younger age; 2) worse disease-specific health status, as assessed with the SGRQ; and 3) having a history of myocardial infarction (table 2). QOC end-of-life care domain scores were comparable for patients with mild to moderate COPD (GOLD stages I-II) and patients with severe to very severe COPD (GOLD stages III-IV) with median score 1.1 (IQR 0.0-2.9) versus 1.4 (0.0-3.4), respectively $(\mathrm{p}=0.42)$.
The QOC item analyses showed that most general communication items, as well as specific end-of-life care communication items, were rated lower by Dutch than US patients (table 3). However, the items "talking about what dying might be like" and "asking about spiritual or religious beliefs" were rated very low in both the Netherlands and the USA. These low scores for communication about end-of-life care are mainly due to the fact that patients reported that these items had not been discussed. Four specific end-of-life care items were less frequently discussed in Dutch than US patients (table 4).

\section{Life-sustaining treatment preferences}

Patients' preferences in their current health state for MV and CPR were similar in the Netherlands and the USA: $70.5 \%$ of Dutch and $58.2 \%$ of US patients reported they would accept invasive MV (adjusted $\mathrm{p}=0.29$ ), and $69.7 \%$ of Dutch and $70.2 \%$ of US patients reported they would accept CPR (adjusted $p=0.18$ ) if needed. Although conversations about life-sustaining treatments with clinicians were not frequent in either

TABLE 1 Demographic and clinical patient characteristics Dutch patients US patients p-value ${ }^{\#}$

\begin{tabular}{|c|c|c|c|}
\hline Subjects $n$ & 122 & 391 & \\
\hline Age yrs & $66.7 \pm 9.3$ & $68.7 \pm 10.0$ & 0.05 \\
\hline Males & $75(61.5)$ & $360(92.1)$ & $<0.001$ \\
\hline Married/living with partner & $88(72.1)$ & $188(48.1)$ & $<0.001$ \\
\hline Caucasian & $122(100)$ & $339(86.7)$ & $<0.001$ \\
\hline High school education or more & $93(76.2)$ & $325(83.1)$ & 0.12 \\
\hline Treated by chest clinician & $122(100)$ & $171(44.5)^{\bullet}$ & $<0.001$ \\
\hline FEV $1 \%$ pred & $37.8(15.5)$ & $43.3(20.2)$ & $<0.01$ \\
\hline \multicolumn{4}{|l|}{ COPD severity } \\
\hline GOLD stage I-II & $25(20.5)$ & $125(32.0)$ & 0.04 \\
\hline GOLD stage III-IV & 97 (79.5) & $266(68.0)$ & 0.02 \\
\hline \multicolumn{4}{|l|}{ Comorbid illnesses } \\
\hline Myocardial infarction & $13(10.7)$ & 75 (19.2) & 0.04 \\
\hline Congestive heart failure & $12(9.8)$ & $61(15.6)$ & 0.15 \\
\hline Stomach ulcer & $14(11.5)$ & $60(15.3)$ & 0.36 \\
\hline Diabetes & $28(23.0)$ & $94(24.0)$ & 0.90 \\
\hline Cancer & $23(18.9)$ & $72(18.4)$ & 1.00 \\
\hline Liver disease & $3(2.5)$ & $36(9.8)^{+}$ & 0.02 \\
\hline \multicolumn{4}{|l|}{ Self-perceived health status } \\
\hline Excellent & $0(0)$ & $4(1.0)^{5}$ & $<0.001$ \\
\hline Very good & $2(1.6)$ & $46(11.9)^{\S}$ & \\
\hline Good & $21(17.2)$ & $128(33.0)^{5}$ & \\
\hline Fair & $80(65.6)$ & $139(35.8)^{\S}$ & \\
\hline Poor & $19(15.6)$ & $71(18.3)^{5}$ & \\
\hline \multicolumn{4}{|l|}{ Disease-specific health status } \\
\hline SGRQ symptoms score & $58.6(22.6)$ & $57.6(23.4)$ & 0.68 \\
\hline SGRQ activity score & $72.9(22.9)$ & $68.5(21.5)$ & 0.06 \\
\hline SGRQ impact score & $43.8(19.1)$ & $39.7(18.1)$ & 0.03 \\
\hline SGRQ total score & $55.1(17.7)$ & $51.4(17.5)$ & 0.04 \\
\hline
\end{tabular}

Data are presented as mean \pm SD or $n(\%)$, unless otherwise stated. Bold indicates statistically significant $\mathrm{p}$-values. FEV1: forced expiratory volume in $1 \mathrm{~s}$; $\%$ pred: \% predicted; COPD: chronic obstructive pulmonary disease; GOLD: Global Initiative for Obstructive Lung Disease; SGRQ: St George's Respiratory Questionnaire. \#: p-values based on Chi-squared or independent-sample t-test; ${ }^{\bullet}: n=384{ }^{+}: n=368 ;{ }^{\S}: n=388$. 
\#

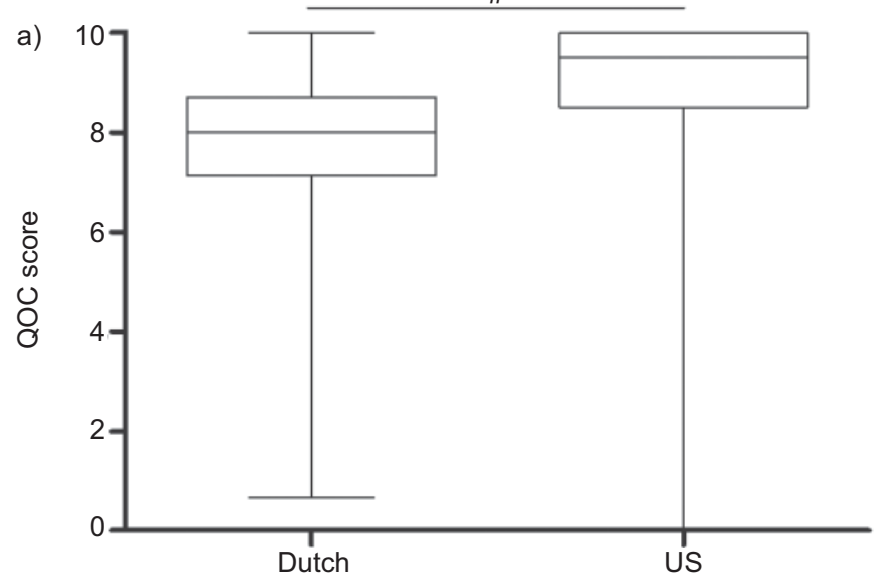

b)

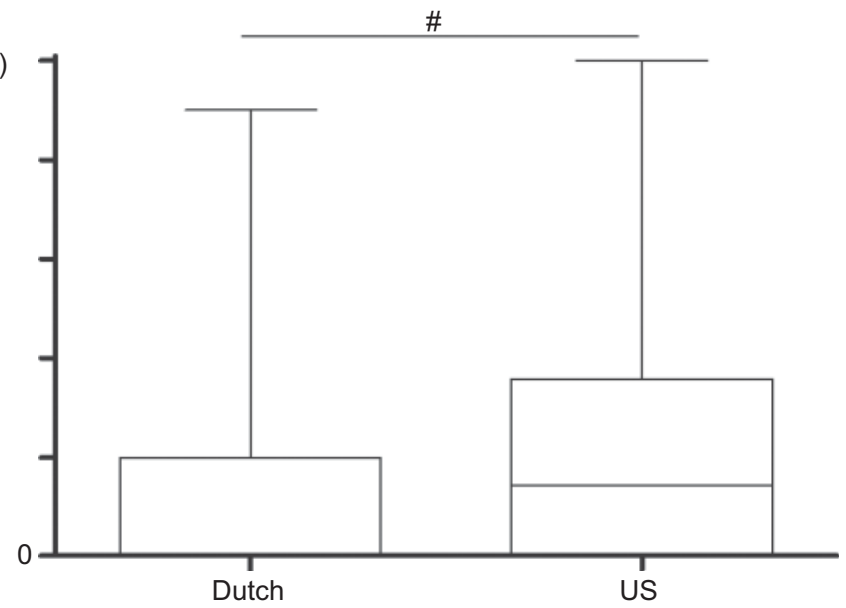

FIGURE 1. Quality of Communication (QOC) questionnaire scores for the a) general communication and b) communication about end-of-life care domains reported by Dutch $(n=122)$ and US $(n=391)$ patients with chronic obstructive pulmonary disease. - : median; boxes represent interquartiles ranges and whiskers represent ranges. \#: $p<0.005$ based on linear regression analysis clustered by clinician (156 clusters), adjusted for age, sex, race, marital status, forced expiratory volume in $1 \mathrm{~s}$, St George's Respiratory Questionnaire total score, medical history of myocardial infarction, congestive heart failure and diabetes.

country, Dutch patients reported having these conversations significantly less often than US patients (12.3 and $17.6 \%$, respectively; adjusted $\mathrm{p}=0.02$ ).

\section{Barriers and facilitators to communication about end-of-life care}

Endorsed barriers and facilitators to end-of-life care communication were different for Dutch and US patients (table 5 and 6). A higher proportion of Dutch than US patients reported: "I don't know what kind of care I want if I get very sick"; "I'm not ready to talk about the care I want if I get very sick";

\begin{tabular}{|c|c|c|c|}
\hline \multirow[t]{2}{*}{ TABLE 2} & \multicolumn{3}{|c|}{$\begin{array}{l}\text { Quality of Communication questionnaire } \\
\text { "communication about end-of-life care" domain } \\
\text { score: association with country using linear } \\
\text { regression and clustered by clinician }\end{array}$} \\
\hline & & $\beta(95 \% \mathrm{Cl})$ & $p$-value \\
\hline \multicolumn{4}{|c|}{ Primary predictor } \\
\hline Country (re & the Netherlands) & $1.03(0.54-1.52)$ & 0.00 \\
\hline \multicolumn{4}{|c|}{ Demographics } \\
\hline Age & & $-0.02(-0.05-0.00)$ & 0.03 \\
\hline Sex (ref: $m$ & & $0.13(-0.34-0.60)$ & 0.58 \\
\hline Marital stat & (ref: living alone) & $0.37(-0.03-0.76)$ & 0.07 \\
\hline Race (ref: & n-Caucasian) & $-0.52(-1.25-0.21)$ & 0.16 \\
\hline \multicolumn{4}{|c|}{ Disease severity } \\
\hline $\mathrm{FEV}_{1} \%$ pre & & $-0.01(-0.02-0.00)$ & 0.31 \\
\hline SGRQ total & ore & $0.02(0.00-0.03)$ & 0.02 \\
\hline \multicolumn{4}{|c|}{ Comorbidities } \\
\hline Myocardial & farction (ref: none) & $0.63(0.01-1.25)$ & 0.05 \\
\hline Congestive & eart failure (ref: none) & $0.26(-0.46-0.97)$ & 0.48 \\
\hline Diabetes ( $r$ & none) & $0.27(-0.16-0.70)$ & 0.21 \\
\hline \multicolumn{4}{|c|}{$\begin{array}{l}n=513 ; r^{2}=0.096, p<0.00005 \text {. Number of clusters: } 156 \text {. Bold indicates } \\
\text { statistically significant data. Ref.: reference category; FEV1: forced expiratory } \\
\text { volume in } 1 \mathrm{~s} ; \% \text { pred: \% predicted; SGRQ: St George's Respiratory } \\
\text { Questionnaire. }\end{array}$} \\
\hline
\end{tabular}

"I don't want to make plans for the future"; and "I have concerns about bringing up assisted suicide". US patients more frequently reported: "I'm not sure which doctor will be taking care of me if I get very sick"; "My ideas about the kind of medical care I want change at different times"; "I have a living will and that means I don't need to talk with my doctor about the care I want if I'm too sick to speak for myself"; and "Doctors look down on people who developed lung/respiratory disease because of smoking" (table 5).

In addition, a higher proportion of US than Dutch patients reported the following facilitators to end-of-life care communication: "My doctor cares about me as a person"; "I worry that I could be a burden on my friends and family if I got very sick"; "I worry about the quality of my life in the future"; "My doctor often asks me about end-of-life care"; "My doctor is very good at talking about end-of-life care"; and "Someone other than my doctor has talked with me about the care I would want if I got too sick to speak for myself". None of the facilitators was more frequently reported by Dutch patients (table 6).

\section{DISCUSSION \\ Overview of findings}

Despite the fact that the Dutch patients with COPD from the present sample had more severe disease, Dutch patients reported communication about end-of-life care as occurring less frequently and rated the quality of this communication lower than US patients. However, prognosis, dying and spiritual issues were rarely discussed by clinicians in both countries. Moreover, in both countries only a minority of the outpatients with COPD had discussed life-sustaining treatment preferences with their clinician. There were also differences in endorsed barriers and facilitators to communication about end-of-life care between Dutch and US patients that may provide direction for future interventions.

\section{Quality of communication about end-of-life care}

The present study shows that quality of patient-clinician communication about end-of-life care was rated low in both the Netherlands and the USA. However, Dutch patients rated 


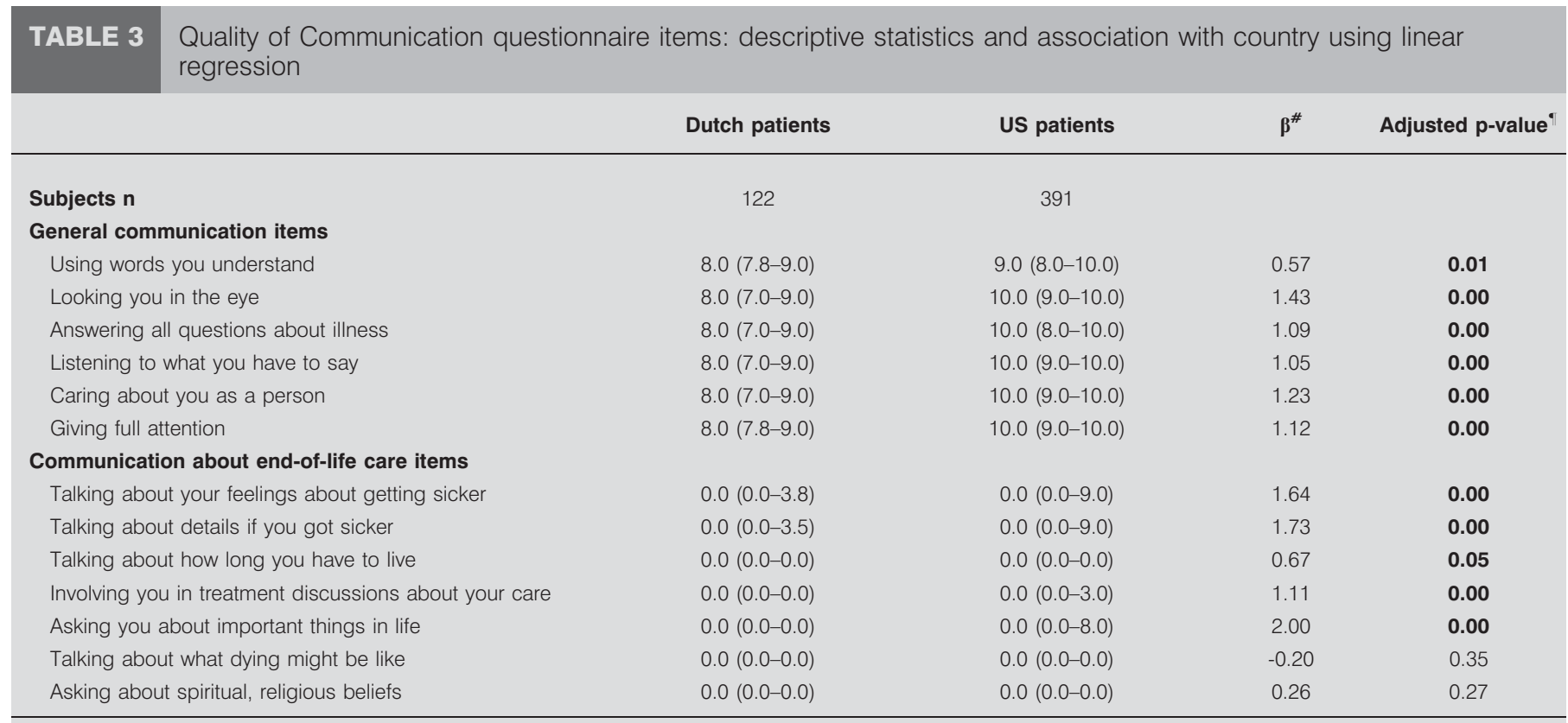

Data are presented as median (interquartile range), unless otherwise stated. Bold indicates statistically significant p-values. \#: reference category was Dutch patients;

$\because$ : based on linear regression analysis clustered by clinician (156 clusters), adjusted for age, sex, race, marital status, forced expiratory volume in $1 \mathrm{~s}$, St George's Respiratory Questionnaire total score, medical history of myocardial infarction, congestive heart failure and diabetes.

quality of communication about end-of-life care even lower than US patients. In contrast to our hypothesis, we found that patients with COPD in the Netherlands were less involved in decision-making about end-of-life care. Interestingly, this was different from what SCHOEN et al. [9] reported concerning involvement in general decision-making. Although reasons for these differences are not clear, previous authors have described differences in the role of autonomy in decisionmaking between the USA and Europe [5, 7, 21]. A more prominent role for autonomy in decision-making may increase the need for or perceived value of timely conversations about life-sustaining treatments in the USA.

Our study confirms the need for enhancing the quality of communication about end-of-life care in the USA and supports this as an even more pressing need for patients with COPD in the Netherlands. Patients with COPD report that clinician communication skills are an important predictor of quality of care [13]. Patients with advanced COPD also report that avoidance of prolonged or unwanted life support is an important element of palliative care [22]. Among patients with cancer, communication about end-of-life care has been associated with improved quality of life at the end of life and reduced intensity of care without any evidence of increased anxiety or depression [23]. In addition, communication about end-of-life care is also associated with higher ratings of the quality of dying, as assessed by bereaved relatives [24]. Finally, a recent randomised trial showed that advance care planning improved satisfaction of patients and families with their care, and reduced stress, anxiety and depression in families of deceased patients [25]. Our study, in the context of these prior studies, suggests that communication about end-of-life care is an important target for improving quality of care for patients with COPD.

\section{Barriers and facilitators to communication about end-of-life care}

Barriers and facilitators to communication about end-of-life care may provide direction for future interventions. We found a number of differences between the Netherlands and the USA in barriers and facilitators reported by patients with COPD. Even though our Dutch sample had more severe disease, a considerably higher proportion of Dutch patients reported that they were not ready to talk about care they want if they got very sick. This may reflect a difference in patients' preferences for communication about prognosis, and should be considered in future studies and efforts to improve communication about endof-life care. One potential approach for discussing prognosis and end-of-life care with patients who are uncomfortable talking about end-of-life care is an indirect approach to the discussion of prognosis [26]. Conversations directed to selfefficacy around disease management as well as quality of life concerns may also enable patients uncomfortable with end-oflife care discussions to find a way to participate and plan for treatments that might be needed if they were to become very ill [27-29]. Furthermore, the barrier "I don't know what kind of care I want if I get very sick" was more frequently endorsed by Dutch patients. This latter barrier has been associated with a lower occurrence of discussions about end-of-life care [4] and, therefore, may be particularly important to address in designing interventions to increase the occurrence of communication about end-of-life care. Finally, prior research has shown that media coverage can influence treatment preferences for patients with COPD and may also be related to some of the regional differences in attitudes about discussing end-of-life care [30].

We found that a higher proportion of US patients reported the barrier that they are not sure which doctor would be taking care of them if they got very sick. SLATORE et al. [13] found that 
TABLE 4 Quality of Communication questionnaire "communication about end-of-life care" items not discussed by clinicians: descriptive statistics and association with country using logistic regression

\begin{tabular}{|c|c|c|c|}
\hline Subjects $n$ & 122 & 391 & \\
\hline \multicolumn{4}{|l|}{ Communication about end-of-life care items } \\
\hline Talking about your feelings about getting sicker & $89(73.0)$ & 208 (53.2) & $0.37(0.21-0.65)$ \\
\hline Talking about details if you got sicker & $89(73.0)$ & $221(56.5)$ & $0.38(0.24-0.60)$ \\
\hline Involving you in treatment discussions about your care & $103(84.4)$ & $271(69.3)$ & $0.35(0.19-0.66)$ \\
\hline Talking about what dying might be like & $108(88.5)$ & $360(92.1)$ & $1.24(0.60-2.54)$ \\
\hline Asking about spiritual, religious beliefs & $111(91.0)$ & $341(87.2)$ & $0.79(0.35-1.77)$ \\
\hline
\end{tabular}

$55 \%$ of patients with COPD who received care from the same clinician for $>5$ yrs reported receiving the best possible care, while only $37 \%$ of the patients who had the same clinician for $<2$ yrs reported receiving the best possible care $(p=0.02)$. Therefore, continuity of care may be an important factor in enhancing quality of patient-clinician communication in the USA. We also found that US patients more frequently reported that "Doctors look down on people who developed lung/ respiratory disease because of smoking". Recently, a qualitative study highlighted the challenge for clinicians to combine

TABLE 5 Endorsed barriers to communication about end-of-life care: descriptive statistics and association with country using logistic regression

Dutch patients $^{\#} \quad$ US patients ${ }^{\#} \quad$ OR $^{*}(95 \% \mathrm{Cl})$

\section{Subjects $n$}

\section{Barriers more common in the Netherlands}

I don't know what kind of care I want if I get very sick

I'm not ready to talk about the care I want if I get very sick

I don't want to make plans for the future

I have concerns about bringing up assisted suicide

\section{Barriers more common in the USA}

I'm not sure which doctor will be taking care of me if I get very sick

My ideas about the kind of medical care I want change at different times

I have a living will, and that means I don't

need to talk with my doctor about the care I

want if I'm too sick to speak for myself

Doctors look down on people who developed

lung/respiratory disease because of smoking

Barriers similar in the Netherlands and the USA

I don't like to talk about getting very sick

My doctor doesn't like to talk about me getting very sick

My doctor never seems to have the time to talk about issues like end-of-life care

I would rather concentrate on staying alive than talk about death

I feel that talking about death can bring death closer

I worry that talking about getting sick is too depressing for my doctor

I have not been very sick
122

391

$92 / 122(75.4)$
$86 / 122(70.5)$
$62 / 122(50.8)$
$35 / 121(28.9)$
$75 / 122(61.5)$
$15 / 122(12.3)$
$16 / 121(13.2)$


$20 / 121(16.5)$

$58 / 122(47.5)$
$15 / 117(12.8)$
$9 / 121(7.4)$
$95 / 122(77.9)$
$20 / 122(16.4)$
$2 / 122(1.6)$
$44 / 122(36.1)$

$193 / 374(51.6)$

110/376 (29.3)

$75 / 382$ (19.6)

50/371 (13.5)

287/378 (75.9)

$160 / 375$ (42.7)

133/381 (34.9)

121/355 (34.1)

165/384 (43.0)

44/271 (16.2)

44/307 (14.3)

295/376 (78.5)

$58 / 381(15.2)$

13/368 (3.5)

167/379 (44.1)
$2.96(1.43-6.14)$

$0.85(0.57-1.25)$

$0.28(0.16-0.48)$

$0.14(0.08-0.25)$

$0.20(0.11-0.37)$

$0.38(0.20-0.72)$

2.01 (1.21-3.36)

5.12 (2.48-10.58)

3.37 (1.87-6.07)

$1.07(0.46-2.48)$

$2.12(0.73-6.16)$

$0.94(0.48-1.82)$

$2.55(0.29-22.41)$

$1.22(0.67-2.21)$
$1.50(0.78-2.89)$

Data are presented as $n$ (\%), unless otherwise stated. Bold indicates statistically significant data. ${ }^{*}: \mathrm{n}$ is variable per item because of patients who responded "don't know" or missing responses; " : based on logistic regression analysis clustered by clinician (156 clusters), adjusted for age, sex, race, marital status, forced expiratory volume in $1 \mathrm{~s}$, St George's Respiratory Questionnaire total score, medical history of myocardial infarction, congestive heart failure and diabetes, using Dutch patients as the reference category. 


\begin{tabular}{|c|c|c|c|c|}
\hline \multirow[t]{2}{*}{ TABLE 6} & \multicolumn{4}{|c|}{$\begin{array}{l}\text { Endorsed facilitators to communication about end-of-life care: descriptive statistics and association with country using } \\
\text { logistic regression }\end{array}$} \\
\hline & & Dutch patients ${ }^{\#}$ & US patients ${ }^{\#}$ & OR $(95 \% \mathrm{Cl})$ \\
\hline Subjects $n$ & & 122 & 391 & \\
\hline \multicolumn{5}{|c|}{ Facilitators more common in the USA } \\
\hline My docto & cares about me as a person & $87 / 119(73.1)$ & 336/358 (93.9) & $5.25(2.28-12.06)$ \\
\hline $\begin{array}{l}\text { I worry th } \\
\text { got ver }\end{array}$ & $\begin{array}{l}\text { I could be a burden on my friends and family if I } \\
\text { sick }\end{array}$ & $59 / 121(48.8)$ & 286/384 (74.5) & $5.19(3.13-8.61)$ \\
\hline I worry at & ut the quality of my life in the future & 47/122 (38.5) & 201/385 (52.2) & $2.56(1.58-4.15)$ \\
\hline My docto & often asks me about end-of-life care & $1 / 122(0.8)$ & $17 / 376(4.5)$ & $9.99(1.37-72.97)$ \\
\hline My docto & is very good at talking about end-of-life care & $8 / 118(6.8)$ & $47 / 290(16.2)$ & $4.87(2.09-11.36)$ \\
\hline $\begin{array}{l}\text { Someone } \\
\text { I would } \\
\text { (like a }\end{array}$ & $\begin{array}{l}\text { ther than my doctor has talked with me about the care } \\
\text { vant if I got too sick to speak for myself } \\
\text { rrse, home health worker, chaplain or clergy, social work }\end{array}$ & $12 / 121(9.9)$ & 150/383 (39.2) & $7.42(3.93-14.01)$ \\
\hline \multicolumn{5}{|c|}{ Facilitators similar in the Netherlands and the USA } \\
\hline I have be & very sick & $75 / 122(61.5)$ & 228/387 (58.9) & $1.13(0.61-2.09)$ \\
\hline I have ha & family or friends who have died & $115 / 122(94.3)$ & $373 / 389(95.6)$ & $1.15(0.50-2.67)$ \\
\hline I trust my & loctor & $115 / 122(94.3)$ & $363 / 378(96.0)$ & $1.02(0.36-2.88)$ \\
\hline My docto & is very good at taking care of lung/respiratory disease & $111 / 120(92.5)$ & 292/319 (91.5) & $0.68(0.29-1.59)$ \\
\hline I feel sure & hat my doctor will be there for me if I get very sick & 106/122 (86.9) & $300 / 366(82.0)$ & $0.65(0.32-1.29)$ \\
\hline
\end{tabular}

Data are presented as $\mathrm{n}(\%)$, unless otherwise stated. Bold indicates statistically significant data. \#: $\mathrm{n}$ is variable per item because of patients who responded "don't know" or missing responses; ": based on logistic regression analysis clustered by clinician (156 clusters), adjusted for age, sex, race, marital status, forced expiratory volume in $1 \mathrm{~s}$, St George's Respiratory Questionnaire total score, medical history of myocardial infarction, congestive heart failure and diabetes, using Dutch patients as the reference category.

health advice on smoking cessation with non-blaming support throughout the course of COPD [31]. Attention to this issue may be relatively more important in US interventions.

End-of-life care discussions occur more frequently if patients perceive that their clinician is good at talking about end-of-life issues [4]. Although US patients report this more frequently than Dutch patients, in both countries only a minority of patients endorsed this facilitator. Previous studies have shown that communication skills-building workshops for clinicians working in oncology can improve communication skills about end-of-life care $[32,33]$. Therefore, this may be a useful intervention to improve communication about end-of-life care in the Netherlands and the USA.

\section{Limitations}

The current project has a number of important limitations. Perhaps most importantly, the difference between the Dutch and US samples could be due to differences other than regional variability. For example, female patients were under-represented in the US sample, while the Dutch sample consisted only of Caucasian patients. Although we used regression analyses to adjust for known differences in patient characteristics, other differences may have been present that were not assessed in the current study, like differences in religion or psychological symptoms. Perception of quality of communication may be influenced by the presence of depression [3]. However, SLATORE et al. [13] showed that QOC scores were not related to the presence of depression symptoms (measured by the Mental Health Inventory-5) or previous self-reported physician diagnosis of depression. Data for the US samples were collected between 1999 and 2002, and between 2004 and 2007, while the data for the Dutch sample were collected in 2008 and 2009. Because data were collected at three different time-points, it is possible that effects may be due to secular trends rather than country differences. Given the absence of any overlap in time among the three samples, it is impossible to assess the extent to which observed differences were primarily functions of sample rather than functions of time. In addition, all Dutch patients were recruited by their chest clinician and rated quality of communication with their chest clinician, while some of the US patients rated quality of communication with the primary care clinician or geriatrician. Although we did not include Dutch primary care physicians, Dutch patients in our sample reported visiting their chest clinicians more frequently than their primary care clinicians. Furthermore, in our study, quality of communication about end-of-life care was not associated with clinician specialty and therefore seems unlikely to be an important confounder. Nevertheless, clinician specialty has been suggested to be related to willingness to discuss end-of-life care issues [34] and it remains unknown whether results would have been comparable if Dutch patients rated quality of communication with their primary care clinician.

There are several other important limitations. First, participants in these studies were volunteers and we do not know whether their views are representative of all patients with COPD. This is an inherent limitation of such research, but should be considered in interpreting the results. Secondly, the present study is based on the patients' perception of quality of communication and does not include objective measures of 
quality of communication. However, we believe that the patients' perception of the quality of communication about end-of-life care is an important construct. Thirdly, the current project compared communication about end-of-life care between the Netherlands and the USA, and it is unknown whether the current Dutch findings are applicable to other European countries. The Netherlands has legalised euthanasia and it is difficult to determine what effect this has on communication about end-of-life care [35]. Furthermore, CARTWRIGHT et al. [34] showed that Dutch clinicians were more likely to discuss purpose of treatment and palliative care compared with clinicians from other European countries. Further research is necessary to study whether and to what extent quality of communication about end-of-life care is comparable between European countries. Finally, the US patients were mainly recruited in one region in the USA and it is unknown if results are comparable with other regions.

\section{Conclusions and future directions}

There is increasing realisation of the importance of communication in the provision of high-quality end-of-life care. Our results suggest that improvements in communication about end-of-life care are needed in both the Netherlands and the USA. We found that conversations about advance care planning occurred for only a minority of outpatients with moderate or severe COPD. Therefore, clinicians caring for patients with COPD in both countries need to pay more attention to communication about end-of-life care. International differences were also notable, with communication about end-of-life care rated lower by Dutch than US patients. It will be important for future studies to collect data concurrently in the two countries in order to produce definitive comparisons of the two locales. Future studies are needed to develop interventions to improve patient-clinician communication about end-of-life care for patients with COPD. These interventions should take into account regional differences in barriers and facilitators to communication about end-of-life care.

\section{SUPPORT STATEMENT}

This project was part of an international research fellowship supported by CIRO+ (Centre of Expertise for Chronic Organ Failure, Horn, the Netherlands). The original Dutch study was supported by: Proteion Thuis (Horn, the Netherlands); CIRO+; grant 3.4.06.082 from the Netherlands Asthma Foundation (Leusden, the Netherlands); and Stichting Wetenschapsbevordering Verpleeghuiszorg (Utrecht, The Netherlands). The original US studies were supported by the Health Services Research and Development, Dept of Veterans Affairs (grant IIR 02-292) and the American Lung Association. J.R. Curtis was funded by a K24 Award from the National Heart, Lung, and Blood Institute (grant K24 HL068593). No funding source had any role in design or conduct of the study; collection, management, analysis, or interpretation of the data; or preparation, review, or approval of the manuscript.

\section{STATEMENT OF INTEREST}

None declared.

\section{REFERENCES}

1 Lopez AD, Shibuya K, Rao C, et al. Chronic obstructive pulmonary disease: current burden and future projections. Eur Respir J 2006; 27: 397-412.

2 Curtis JR. Palliative and end-of-life care for patients with severe COPD. Eur Respir J 2008; 32: 796-803.
3 Curtis JR, Engelberg RA, Nielsen EL, et al. Patient-physician communication about end-of-life care for patients with severe COPD. Eur Respir J 2004; 24: 200-205.

4 Knauft E, Nielsen EL, Engelberg RA, et al. Barriers and facilitators to end-of-life care communication for patients with COPD. Chest 2005; 127: 2188-2196.

5 Moselli NM, Debernardi F, Piovano F. Forgoing life sustaining treatments: differences and similarities between North America and Europe. Acta Anaesthesiol Scand 2006; 50: 1177-1186.

6 Wunsch H, Linde-Zwirble WT, Harrison DA, et al. Use of intensive care services during terminal hospitalizations in England and the United States. Am J Respir Crit Care Med 2009; 180: 875-880.

7 Fassier T, Lautrette A, Ciroldi M, et al. Care at the end of life in critically ill patients: the European perspective. Curr Opin Crit Care 2005; 11: 616-623.

8 White DB, Curtis JR. Care near the end-of-life in critically ill patients: a North American perspective. Curr Opin Crit Care 2005; 11: 610-615.

9 Schoen C, Osborn R, How SK, et al. In chronic condition: experiences of patients with complex health care needs, in eight countries, 2008. Health Aff (Millwood) 2009; 28: w1-w16.

10 Economist Intelligence Unit. The Quality of Death: Ranking Endof-Life Care Across the World. www.eiu.com/site_info.asp?info_ name $=$ qualityofdeath_lienfoundation\&page $=$ noads\& $r f=0$ Date last accessed: July 31, 2010. Date last updated: July 12, 2010.

11 Janssen DJ, Wouters EF, Schols JM, et al. Self-perceived symptoms and care needs of patients with severe to very severe chronic obstructive pulmonary disease, congestive heart failure or chronic renal failure and its consequences for their closest relatives: the research protocol. BMC Palliat Care 2008; 7: 5.

12 Janssen DJ, Spruit MA, Schols JM, et al. A call for high-quality advance care planning in outpatients with severe COPD or chronic heart failure. Chest 2011; 139: 1081-1088.

13 Slatore CG, Cecere LM, Reinke LF, et al. Patient-clinician communication: associations with important health outcomes among veterans with COPD. Chest 2010; 138: 628-634.

14 Rabe KF, Hurd S, Anzueto A, et al. Global strategy for the diagnosis, management, and prevention of chronic obstructive pulmonary disease: GOLD executive summary. Am J Respir Crit Care Med 2007; 176: 532-555.

15 Engelberg R, Downey L, Curtis JR. Psychometric characteristics of a quality of communication questionnaire assessing communication about end-of-life care. J Palliat Med 2006; 9: 1086-1098.

16 Stapleton RD, Nielsen EL, Engelberg RA, et al. Association of depression and life-sustaining treatment preferences in patients with COPD. Chest 2005; 127: 328-334.

17 Standardization of Spirometry, 1994 Update. American Thoracic Society. Am J Respir Crit Care Med 1995; 152: 1107-1136.

18 Nguyen HQ, Donesky-Cuenco D, Carrieri-Kohlman V. Associations between symptoms, functioning, and perceptions of mastery with global self-rated health in patients with COPD: a cross-sectional study. Int J Nurs Stud 2008; 45: 1355-1365.

19 Jones PW, Quirk FH, Baveystock CM, et al. A self-complete measure of health status for chronic airflow limitation. The St. George's Respiratory Questionnaire. Am Rev Respir Dis 1992; 145: 1321-1327.

20 Altman DG, Gore SM, Gardner MJ, et al. Statistical guidelines for contributors to medical journals. Br Med J (Clin Res Ed) 1983; 286: 1489-1493.

21 Luce JM, Lemaire F. Two transatlantic viewpoints on an ethical quandary. Am J Respir Crit Care Med 2001; 163: 818-821.

22 Rocker GM, Dodek PM, Heyland DK. Toward optimal end-of-life care for patients with advanced chronic obstructive pulmonary disease: insights from a multicentre study. Can Respir J 2008; 15: 249-254.

23 Wright AA, Zhang B, Ray A, et al. Associations between end-of-life discussions, patient mental health, medical care near death, and caregiver bereavement adjustment. JAMA 2008; 300: 1665-1673. 
24 Patrick DL, Curtis JR, Engelberg RA, et al. Measuring and improving the quality of dying and death. Ann Intern Med 2003; 139: 410-415.

25 Detering KM, Hancock $\mathrm{AD}$, Reade MC, et al. The impact of advance care planning on end of life care in elderly patients: randomised controlled trial. BMJ 2010; 340: c1345.

26 Curtis JR, Engelberg R, Young JP, et al. An approach to understanding the interaction of hope and desire for explicit prognostic information among individuals with severe chronic obstructive pulmonary disease or advanced cancer. J Palliat Med 2008; 11: 610-620.

27 Goldstein NE, Back AL, Morrison RS. Titrating guidance: a model to guide physicians in assisting patients and family members who are facing complex decisions. Arch Intern Med 2008; 168: 1733-1739.

28 Steinhauser KE, Alexander SC, Byock IR, et al. Do preparation and life completion discussions improve functioning and quality of life in seriously ill patients? Pilot randomized control trial. J Palliat Med 2008; 11: 1234-1240.

29 Ford D, Zapka J, Gebregziabher M, et al. Factors associated with illness perception among critically ill patients and surrogates. Chest 2010; 138: 59-67.
30 Nava S, Santoro C, Grassi M, et al. The influence of the media on COPD patients' knowledge regarding cardiopulmonary resuscitation. Int J Chron Obstruct Pulmon Dis 2008; 3: 295-300.

31 Halding AG, Heggdal K, Wahl A. Experiences of self-blame and stigmatisation for self-infliction among individuals living with COPD. Scand J Caring Sci 2011; 25: 100-107.

32 Back AL, Arnold RM, Baile WF, et al. Efficacy of communication skills training for giving bad news and discussing transitions to palliative care. Arch Intern Med 2007; 167: 453-460.

33 Jenkins V, Fallowfield L, Solis-Trapala I, et al. Discussing randomised clinical trials of cancer therapy: evaluation of a Cancer Research UK training programme. BMJ 2005; 330: 400.

34 Cartwright C, Onwuteaka-Philipsen BD, Williams G, et al. Physician discussions with terminally ill patients: a cross-national comparison. Palliat Med 2007; 21: 295-303.

35 van der Heide A, Onwuteaka-Philipsen BD, Rurup ML, et al. Endof-life practices in the Netherlands under the Euthanasia Act N Engl J Med 2007; 356: 1957-1965. 